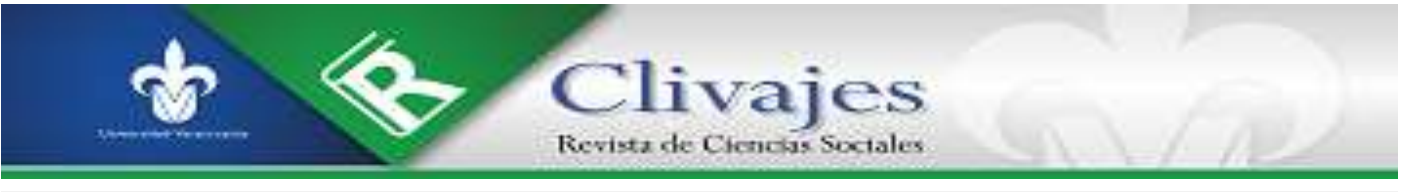

Jorge Luis Triana Sánchez

jorgetriana@outlook.com

Universidad Autónoma de Guerrero

SEGURIDAD PÚBLICA, VIOLENCIA URBANA Y PREVENCIÓN SOCIAL DEL DELITO EN ACAPULCO, GUERRERO, MÉXICO

DOI: https://doi.org/10.25009/clivajes-rcs.v0i14.2674

Clivajes. Revista de Ciencias Sociales. Año VII, número 14, julio-diciembre 2020, pp. 229-261.

https://clivajes.uv.mx/index.php/Clivajes/article/view/2674/4485

Instituto de Investigaciones Histórico-Sociales, Universidad Veracruzana

Clivajes. Revista de Ciencias Sociales/ISSN: 2395-9495/IIH-S, UV/Xalapa, Veracruz, México

Recibido: 12/11/2019

Aceptado: 14/12/2019

Dictaminado: 01/09/2020

Clivajes. Revista de Ciencias Sociales (ISSN: 2395-9495), Año VII, Núm. 14, julio-diciembre, 2020

Instituto de Investigaciones Histórico-Sociales, Universidad Veracruzana, México 


\title{
SEGURIDAD PÚBLICA, VIOLENCIA URBANA Y PREVENCIÓN SOCIAL DEL DELITO EN ACAPULCO, GUERRERO, MÉXICO
}

\author{
Jorge Luis Triana Sánchez*
}

\begin{abstract}
Resumen
Acapulco constituye un caso paradigmático de la violencia delincuencial en México; en los últimos años se ha consolidado como una de las ciudades más violentas del mundo y uno de los municipios con mayor número de delitos de alto impacto en el país. Este trabajo plantea un diagnóstico sobre incidencia delictiva y percepción de inseguridad, a partir de una discusión conceptual sobre las instituciones de seguridad y justicia, y su papel en la política criminal, así como de una revisión de la política de prevención implementada en el marco del Programa Nacional de Prevención del Delito (PRONAPRED), mediante acciones focalizadas en cinco polígonos de atención prioritaria en Acapulco. Como estrategia metodológica, recurre al análisis de datos de fuentes primarias, que se obtienen mediante encuesta aplicada en 2016 y 2019, en dichos polígonos, con muestreos probabilísticos, y también de fuentes secundarias en materia de seguridad pública, procuración e impartición de justicia y sistema penitenciario; desarrolla, además, una evaluación del diseño del PRONAPRED, a través de la revisión de los anexos únicos de coordinación y adhesión para el otorgamiento de apoyos de los años 2013 al 2018. Los resultados del estudio apuntan a que los recursos no se asignaron mediante criterios racionales ni objetivos, sino que financiaron acciones sin una relación clara con la prevención de la violencia y la delincuencia; acciones con impactos difíciles de medir, acciones que servían de insumo para otras acciones que en realidad no eran tomadas en cuenta y acciones que corresponden a instancias ajenas a la prevención del delito.
\end{abstract}

Palabras clave: Política criminal, Prevención social, Incidencia delictiva, Percepción de inseguridad, Sistema de justicia penal

\section{Public security, urban violence and social prevention of crime in Acapulco, Guerrero, Mexico}

\begin{abstract}
Summary
Acapulco is a paradigmatic case of criminal violence in Mexico. In recent years it has become one of the most violent cities in the world and one of the municipalities with the highest number of high-impact crimes in the country. This work proposes a diagnosis of crime incidence and perception of insecurity, based on a conceptual discussion of security and justice institutions and their role in criminal policy, as well as a review of the prevention policy implemented in the framework of the National Program for Crime Prevention (PRONAPRED), through targeted actions in five priority areas in Acapulco. As a methodological strategy, it resorts to the analysis of data from primary sources, obtained through a survey applied in 2016 and 2019 in these polygons with probabilistic sampling, and also from secondary sources on public safety, procurement and administration of justice and prison system. It also develops an evaluation of the design of PRONAPRED, through the review of the single annexes of coordination and adhesion for the granting of support from 2013 to 2018. The results of the study point to the fact that resources were not allocated through rational and objective criteria, but rather financed actions without a clear relationship with the prevention of violence and crime; actions with impacts that were difficult to measure, actions that served as input for other actions that were not actually taken into account, and actions that correspond to agencies outside of crime prevention.
\end{abstract}

Keywords: Criminal policy, Social prevention, Incidence of crime, Perception of insecurity, Criminal justice system

* Doctor en Política Pública por el Instituto Tecnológico y de Estudios Superiores de Monterrey. Profesor-Investigador Cátedra CONACYT-Universidad Autónoma de Guerrero; miembro del Sistema Nacional de Investigadores. Contacto: jorgetriana@outlook.com.

Clivajes. Revista de Ciencias Sociales (ISSN: 2395-9495), Año VII, Núm. 14, julio-diciembre, 2020 Instituto de Investigaciones Histórico-Sociales, Universidad Veracruzana, México 


\title{
Sécurité Publique, violence urbaine et prévention sociale du délit à Acapulco, Guerrero, Mexique
}

\begin{abstract}
Résumé
Acapulco constitue un cas paradigmatique de la violence délictueuse au Mexique ; au cours des dernières années cette ville s'est constituée comme une des plus violentes du monde et une municipalité qui compte avec un grand nombre de délits de grand impact dans le pays. Ce travail propose un diagnostic sur l'incidence délictueuse et perception d'insécurité, à partir d'une discussion conceptuelle sur les institutions de sécurité et justice, et leur rôle dans la politique criminelle, il s'agit aussi d'une révision de la politique de prévention implémentée dans le cadre du Programme National de Prévention du Délit (PRONAPRED, par se sigles en espagnol) à travers des actions focalisées dans cinq polygones d'attention prioritaire à Acapulco. Comme stratégie méthodologique, ce travail fait appel à l'analyse de données de sources primaires, qui sont obtenues à travers des enquêtes appliquées en 2016 et 2019 dans ces polygones avec des échantillonnages probabilistes et aussi de sources secondaires en matière de sécurité publique, procuration et impartition de justice et système pénitentiaire ; il développe en plus, une évaluation du dessin du PRONAPRED, à travers la révision des annexes uniques de coordination et d'adhésion pour la remise d'appuis dans les années 2013 au 2018. Les résultats de l'étude visent envers la non attribution des ressources au moyen des critères rationnels et objectifs, sinon qu'elles ont financé des actions sans aucun clair rapport avec la prévention de la violence et de la délinquance ; des actions avec des impacts difficiles à mesurer, des actions qui servaient comme intrant pour d'autres actions qui en réalité n'étaient pas prises en compte et des actions qui correspondaient à des instances étrangères à la prévention du délit.
\end{abstract}

Mots clés : Politique criminelle, Prévention sociale, Incidence délictueuse, Perception d'insécurité, Système de justice pénale

\section{INTRODUCCIÓN}

En los últimos años, el incremento significativo de diversas expresiones de violencia y delincuencia se ha extendido en todo México, sobre todo en sus principales centros urbanos, generando la necesidad de impulsar políticas públicas para promover la seguridad desde el ámbito federal, con un enfoque de prevención social y atendiendo de manera focalizada las particularidades locales. En este contexto de intervención pública en materia de violencia y delincuencia, Acapulco representa un caso paradigmático, al ser una de las ciudades más violentas del mundo y uno de los municipios con mayor incidencia de delitos de alto impacto en el país.

El objetivo general de este trabajo es presentar un diagnóstico sobre la incidencia delictiva y la percepción de inseguridad en Acapulco, así como una evaluación y un análisis de la política de prevención del delito implementada en el municipio a través de programas federales, con el fin de coadyuvar al diseño integral de alternativas en el corto, mediano y largo plazo. Se propone, como objetivos particulares, identificar las condiciones sociales en las que se desarrolla la violencia criminal y la forma en que han sido atendidas por los programas institucionales, así como establecer el nivel de inseguridad que perciben los ciudadanos y cómo les afecta en sus actividades cotidianas. 
El análisis se centra en las acciones implementadas en el marco del Programa Nacional de Prevención del Delito (PRONAPRED), un subsidio federal que financió acciones de prevención de naturaleza social, comunitaria, situacional y focalizada, en aquellos municipios de atención prioritaria a nivel nacional, entre los cuales se encontraba, por supuesto, Acapulco. Los lineamientos del programa promovían la focalización de las acciones, mediante la atención de polígonos geográficos de atención prioritaria en cada municipio; en el caso de Acapulco, las autoridades locales definieron cinco polígonos, ubicados en distintas colonias, a los cuales se benefició con acciones de prevención en el período 2013-2018; éstos son conocidos como Petaquillas, Renacimiento, Zapata, Progreso y Jardín. Si bien durante dicho período existían otros fondos federales para financiar la prevención del delito, como el Fondo de Aportaciones para la Seguridad Pública (FASP) en los estados y municipios y el Subsidio para la Seguridad de los Municipios (SUBSEMUN), el PRONAPRED fue el único fondo presupuestal destinado exclusivamente a programas de prevención.

En este artículo, se documentan elementos conceptuales, estrategias metodológicas y resultados de investigación en materia de seguridad pública y violencia criminal en el municipio de Acapulco, durante el período 2015-2019. En los primeros tres apartados, se discuten los conceptos críticos para el análisis, con base en las distintas facetas de la política criminal, como la prevención y contención del delito, la procuración e impartición de justicia, y la reinserción social; en el cuarto apartado, se exponen las estrategias metodológicas utilizadas para la recopilación y análisis de información; el quinto apartado contiene los principales hallazgos empíricos en términos del diagnóstico y de la evaluación del diseño de la política de prevención, específicamente de las acciones implementadas por el PRONAPRED; en el último apartado, se exponen las conclusiones.

\section{ELEMENTOS CONCEPTUALES DE LA SEGURIDAD CIUDADANA}

La seguridad, en su significado más amplio, implica un estado social caracterizado por la ausencia de amenazas sobre los bienes y derechos de los individuos (García, 2002, p. 81). Partiendo de este significado, se distinguen dos sentidos posibles de la seguridad: uno, como un fin que justifica limitaciones a las libertades de los ciudadanos, al imponer límites a comportamientos dañinos; dos, como un derecho que merece ser tutelado por el Estado frente a los poderes públicos y frente a la criminalidad; sin embargo, en situaciones donde los altos niveles de delincuencia representan uno de los principales problemas sociales, la seguridad, como derecho, puede soslayar la tutela frente a los 
poderes públicos para dar prioridad a la tutela frente a la criminalidad, utilizando, como herramienta primordial, la limitación de las libertades de los individuos (Bernardi, 2010). La variedad de posibles situaciones de alta criminalidad provoca la emergencia de términos accesorios como "seguridad pública”, “ciudadana”, “urbana”, “jurídica”, “nacional", "humana”, entre otros, en función de los tipos de delitos o situaciones que prevalezcan y causen un sentido de urgencia social.

En particular, la seguridad pública es acotada por Calveiro (2012) como el “conjunto de políticas que procuran garantizar un determinado orden mediante la prevención y represión de lo que dentro de un sistema hegemónico ${ }^{1}$ en particular se consideran delitos y faltas" (p. 171). En otras palabras, "seguridad pública" es un término que emerge ante un sentido de urgencia colectiva, debido a la vulneración de lo que el consenso social y el poder político consideran valioso.

En términos normativos, el artículo 21 de la Constitución Federal indica que la seguridad pública "es una función a cargo de la Federación, las entidades federativas y los municipios"; sus fines, según el artículo 2 de la Ley General del Sistema Nacional de Seguridad Pública (SNSP), son "salvaguardar la integridad y derechos de las personas, así como preservar las libertades, el orden y la paz públicos y comprende la prevención especial y general de los delitos, la investigación para hacerla efectiva, la sanción de las infracciones administrativas, así como la investigación y la persecución de los delitos y la reinserción social del individuo". Para lograr dicho cometido, el Estado cuenta con diversas instituciones en materia de seguridad y justicia, las cuales se encargan de las labores de contención del delito, procuración e impartición de justicia, y reinserción social (Salgado, 2010, p. 1), y encuentran soporte en la legislación, los cuerpos de policía, la justicia y el sistema penitenciario (Calveiro, 2012, p. 171).

Al conjunto de medidas encargadas de promover la seguridad pública se le conoce como política criminal: "una sección de la política pública destinada a la planificación, ejecución y control de lineamientos preventivos y represivos en la lucha de la criminalidad” (Añez \& Han, 2011, p. 21); en concreto, la política criminal refiere todas aquellas medidas implementadas por el Estado, cuyo objeto es "la prevención de acciones humanas consideradas delitos" (Sánchez-Ostiz, 2007, p. 60), mediante las instituciones de seguridad y justicia.

La política criminal adquiere una naturaleza estrictamente penal al ser implementadas por las instituciones de seguridad y justicia. Un concepto más amplio es

${ }^{1}$ El énfasis proviene de la fuente y se debe, en parte, a que la definición del delito y la graduación de su gravedad se conciben como producto de un consenso social que puede ser manipulado mediante el poder político (Calveiro, 2012, p. 173). 
el de política criminológica, la cual consiste en el conjunto de políticas sociales y penales, formuladas por el Estado, para a la prevención de las causas, tanto individuales como sociales, de la delincuencia y la violencia, siendo las políticas penales el ejercicio de la función punitiva del Estado, a través de la aplicación de la ley penal, y la ejecución de las penas y medidas de seguridad, en respuesta al fenómeno criminal (Chincoya, 2013). Estas políticas penales se adhieren a lo que Azaola y Ruiz (2009, p. 5) entienden por política criminal, la cual reúne a las "ciencias penales, penitenciarias, policiales y, finalmente, al aparato jurisdiccional punitivo del Estado, así como a todas las políticas de intervención social de control", con la pena de privación de la libertad como instrumento principal; por lo tanto, la política criminal se ve contenida en la política criminológica, que se complementa con otras medidas de prevención social.

\section{LAS INSTITUCIONES DE SEGURIDAD Y JUSTICIA}

En la noción de política criminal, como medida exclusivamente penal, la contención del delito le corresponde a los cuerpos de policía - el primer eslabón del aparato punitivo del Estado-, encargados de disuadir la comisión del delito, contener el daño o peligro de uno en curso e inhabilitar al infractor del consumado. Un elemento crítico en el desempeño de la función policial es, entonces, si la política criminal que prescribe sus intervenciones ha sido definida con criterios racionales y estables a través del tiempo, o si resulta más bien reactiva e inestable. Al respecto, Añez y Han (2011) identifican algunos factores que contribuyen a una política criminal reactiva e ineficiente, en cuanto a la prevención y el combate a la delincuencia: un conocimiento inapropiado del fenómeno criminal, una inadecuada distribución de recursos, falta de continuidad en la planeación de las políticas públicas, ausencia de evaluación y seguimiento de éstas, y falta de consistencia y estabilidad con respecto a la visión de la prevención. Tamarit (2007) señala, además, que la falta de racionalidad se debe al aumento de la dinámica punitivista, ${ }^{2}$ a la ausencia de una cultura de evaluación, la falta de atención a la criminología y, en general, a una falta de consideración de los operadores de la política hacia los expertos, lo que provoca una política criminal carente de bases empíricas sólidas.

La confianza en los cuerpos de policía también representa un factor determinante en la política criminal, ya que, al no existir confianza, los ciudadanos podrían dejar de recurrir a las formas de protección institucionales e inducir, además, situaciones sociales ineficientes, aumentando, por ejemplo, el gasto en seguridad privada (u otras medidas de protección para prevenir el delito), aun cuando el Estado hubiera realizado las asignaciones presupuestales pertinentes para seguridad pública. Se requiere de la

${ }^{2}$ En otras palabras, la compulsión o propensión al castigo como solución a todos los conflictos sociales por parte de la autoridad. 
confianza del ciudadano, asimismo, para acceder a la noticia de la comisión de un delito, pues la desconfianza en los cuerpos de policía es un factor determinante en la "cifra negra”, término comúnmente utilizado para describir la no-denuncia (Quinteros, 2014).

A pesar de la función de contención y disuasión de los cuerpos de policía, puede registrarse incidencia delictiva. Es necesaria, entonces, la procuración de justicia, que recae en las procuradurías o fiscalías de los estados y la federación, para los delitos tanto del fuero común como del fuero federal. Estas instituciones están a cargo de la investigación ministerial, los servicios periciales y el Ministerio Público (Salgado, 2010). Este último tiene la función de perseguir delitos, mediante la recolección de pruebas, argumentos, y fundamentos jurídicos que permitan que el responsable de un delito sea sancionado por un juez; para ello, emprende una investigación ministerial y se auxilia, en caso de requerirse, de los servicios periciales (De la Barreda, Aguilar, Vélez, \& Chávez, 2013, p. 2).

Las entidades de procuración de justicia, tanto a nivel estatal como federal, han formado parte de los poderes ejecutivos. Sin embargo, a raíz de la reforma constitucional de 2008 en materia de seguridad y justicia, se hizo necesaria una modernización institucional para dotar de autonomía al Ministerio Público y permitirle un ejercicio congruente con los principios acusatorios del Nuevo Sistema de Justicia Penal. A nivel federal, la reforma político-electoral de 2014 proyectó la transición de la Procuraduría General de la República a una Fiscalía General de la República autónoma, con personalidad jurídica y patrimonio propios.

A nivel estatal, y siguiendo la esencia de la transición federal, 27 entidades federativas han transformado su Procuraduría en Fiscalía (Conferencia Nacional de Procuración de Justicia, 2019), incluyendo Guerrero. ${ }^{3}$ Con la expedición, en 2014, de la Ley Orgánica de la Fiscalía General del Estado de Guerrero, se le instauró como órgano público con autonomía para desarrollar la función de investigación y persecución de los delitos del fuero común, el ejercicio de la acción penal y la defensa de los intereses de la sociedad a través del Ministerio Público.

Para las entidades de procuración de justicia, la política criminal persigue el objetivo de disminuir la incidencia delictiva, mediante el diseño, implementación, evaluación y seguimiento de acciones concretas de investigación y persecución del delito, optimizando recursos humanos y materiales, y preservando la legitimidad de sus actuaciones (Torres, 2014, pp. 4-5). Sin embargo, las limitadas capacidades, no solamente de las procuradurías o fiscalías, sino de todo el sistema de justicia penal, reducen la procuración de justicia a un proceso de definición de prioridades (Hulsman, 2014). En efecto, la política criminal requiere determinar "qué bienes jurídicos precisan de protección penal, o qué otros medios menos gravosos, distintos de la persecución penal y del encarcelamiento, pueden ser suficientes y eficaces para la protección de los

${ }^{3}$ No obstante, los diagnósticos iniciales de este supuesto cambio siguen apuntando a una falta de independencia de la Fiscalía del Estado. Véase Open Society Justice Initiative (2015, pp. 27-29). 
bienes jurídicos fundamentales y la seguridad pública” (Caldas, 2014, p. 313). Esta discrecionalidad de las entidades de procuración de justicia representa una oportunidad para contrarrestar la criminalización excesiva, si se utiliza con criterios racionales, a través de su capacidad selectiva en cuanto a los delitos a perseguir, los imputados a investigar y las víctimas a proteger (Zaffaroni, Alagia \& Slokar, 2002, pp. 7-8).

Sin embargo, la denuncia e investigación de los delitos requiere, como complemento, la impartición de justicia; la prohibición de hacerla por cuenta propia deriva en la obligación, del Estado, de otorgarla de manera pronta, completa e imparcial, al tenor del artículo 17 de la Constitución federal. Dicha impartición de justicia corre a cargo de los poderes judiciales estatales para los delitos del fuero común, y del Poder Judicial de la Federación para los delitos del fuero federal (Salgado, 2010, p. 2). Esta tarea, antes de la reforma constitucional de 2008 y presumiblemente hasta la fecha en algunos casos, ha sido acusada de lenta, injusta, desequilibrada, irregular e informal. ${ }^{4}$

La reforma constitucional de 2008 trajo cambios radicales en la impartición de justicia, al convertir al poder judicial en el contrapeso de otros actores del sistema, con la creación de las figuras de juez de control, juez de juicio oral y juez de ejecución de sentencias, en sustitución de un juez único, que conocía la causa en el sistema anterior en todas sus etapas. El juez de control verifica las actuaciones del Ministerio Público y la policía, determinando qué pruebas pueden desahogarse en el juicio oral, presidido por un juez distinto para dar cumplimiento cabal al mandato del artículo 20 constitucional, que refiere que "el juicio se celebrará ante un juez que no haya conocido del caso previamente". Por otro lado, el juez de ejecución de sentencias será el encargado de controlar las actuaciones de la administración penitenciaria. Otros cambios importantes son la desaparición de los secretarios de acuerdos y la aparición (en algunos casos) de la figura de administrador de tribunal (Torres, 2011, p. 115).

La confianza en las instituciones de impartición de justicia, como en otras instancias del sistema de justicia penal, además de ser fuente de legitimidad ante la sociedad, influye en la probabilidad de que los ciudadanos denuncien. Sin embargo, el cambio de paradigma de medidas cautelares que acompaña al sistema de justicia penal acusatorio pudiera provocar una deslegitimación en la impartición de justicia, ya que la sociedad está acostumbrada a la prisión preventiva y observa con malos ojos el hecho de que un individuo acusado de un delito pueda llevar su proceso en libertad, pues genera una percepción de impunidad.

El último eslabón de la seguridad y la justicia es la reinserción social, a cargo del sistema penitenciario, al cual corresponde la ejecución de las sentencias dictadas por el poder judicial, tanto a nivel estatal como federal (Salgado, 2010). La situación crítica del sistema carcelario de nuestro país - con problemas de sobrepoblación y hacinamiento penitenciarios-, ha sido ampliamente documentada por la sociedad, el gobierno y la

${ }^{4}$ Véase Guillén y Cruz (2008) para una descripción certera de los vicios del sistema de justicia penal previo a la reforma. 
academia. La Oficina de las Naciones Unidas contra la Droga y el Delito (UNODC, 2010), explica que la situación de los centros de reclusión no depende sólo de las autoridades penitenciarias, sino también del proceder en todas las etapas previas de la justicia penal, pues "cuando los gobiernos adoptan un enfoque punitivo, sin tratar de eliminar los factores que dan lugar a conductas delictivas, los centros penitenciarios acaban convirtiéndose en lugares que albergan a un número elevado de personas procedentes de los grupos más vulnerables y desfavorecidos de la sociedad, junto con un número muy inferior de delincuentes peligrosos y violentos" (p. 1).

Este enfoque punitivo tiene su origen en nuestra legislación. En México, aproximadamente el $95 \%$ de los delitos contemplan la pena de prisión (98\% para el estado de Guerrero), dando origen a una vida social muy criminalizada. El derecho penal dista mucho de ser el último recurso de las controversias y conflictos sociales (Zepeda, 2012); de hecho, esta tendencia criminalizadora ha desviado hacia el derecho penal controversias que antes pertenecían a otras ramas del derecho, tal es el caso de algunos conflictos familiares o mercantiles.

La Organización de las Naciones Unidas (ONU) establece parámetros básicos del sistema penitenciario para una reinserción social eficaz con plena protección de los derechos humanos. Estos parámetros comprenden aspectos de ingreso y evaluación de los reclusos (explicación de reglamentos, valoración inicial), sus condiciones de vida (alojamiento, higiene, vestimenta y alimentación), asistencia sanitaria (acceso y cobertura), contacto con el mundo exterior (visitas familiares, conyugales y telecomunicación), régimen carcelario (planeación individual de la pena, acceso a servicios educativos, de capacitación para el trabajo, actividades productivas y de ocio; terapias para conductas delictivas, preparativos para puesta en libertad y servicios religiosos), vigilancia y seguridad (medidas de seguridad, disciplina y sanciones), y procedimientos de presentación de quejas (UNODC, 2010, pp. 9-26).

Como indica Ojeda (2012, pp. 70-71), esta integralidad del tratamiento penitenciario otorga al individuo un sentido de utilidad y temple de la disciplina, combate la ignorancia y encauza el libre albedrío; además, reduce la agresividad, mejora el nivel cultural y las condiciones psicofísicas; constituye un apoyo moral y confort espiritual; reduce la sensación de aislamiento, conserva las relaciones sociales, conyugales y familiares, y ayuda a superar las diversas formas de inadaptación desde sus causas para vivir apropiadamente en sociedad.

Actualmente, las instituciones de reinserción social no sólo enfrentan el reto de la criminalidad como fenómeno socioeconómico, político y cultural, sino también el estigma de la cárcel como reproductora de la violencia y el conflicto, por lo cual se ven en la necesidad de recurrir a métodos de prevención, protección y asistencia, alternativos al medio penitenciario, que minimicen el uso de la prisión (Acosta, 2011, p. 117). La búsqueda de mecanismos alternativos a la prisión se justifica, además, porque transitar por el sistema penitenciario puede devaluar a las personas en determinados contextos 
sociales, donde se les asigna, por ejemplo, un estatus social inferior, de personas “riesgosas” o “poco confiables" (Pérez, 2013), provocándoles dificultades tanto para conseguir un empleo legal como para establecer relaciones interpersonales, ya que, a pesar de los esfuerzos normativos para promover sistemas de justicia penal garantistas, la realidad procesal y penitenciaria sigue siendo "selectiva, criminalizadora, estigmatizadora y sin ninguna utilidad" (Gutiérrez, 2014, p. 71).

\section{CONCEPTOS, ENFOQUES Y TEORÍAS DE PREVENCIÓN}

Aunque en teoría cualquier política pública orientada a reducir la delincuencia pudiera considerarse una política de prevención, en la práctica la mayoría de estas políticas distinguen entre prevención y otros términos como disuasión, incapacitación, rehabilitación e incremento de medidas de seguridad (Greenwood, 2004); en la literatura se ha debatido ampliamente la relación entre los conceptos de prevención y control.

Una vertiente de la discusión distingue, como posiciones opuestas, la prevención y el control; la primera, basada en una perspectiva epidemiológica y de salud pública, y el segundo, en una perspectiva criminológica y judicial. Así, las políticas de prevención se fundan en el combate a la pobreza, incidiendo en factores sociales o estructurales, con programas específicos o integrales dirigidos a toda la población (prevención primaria), a grupos en riesgo (prevención secundaria) o a víctimas y agresores (prevención terciaria), en tanto que las políticas de control operan mediante sanciones penales que requieren intervención legislativa, policiaca, de procuración e impartición de justicia, y penitenciaria (Fuentes, 2003)

La vertiente de Ayos (2014) considera la dicotomía conceptual entre represión y prevención, que deriva, a su vez, en la dicotomía operacional entre pena y medidas de prevención, donde estas últimas adoptan los enfoques de prevención social y situacionalambiental, cuya construcción se debe a medidas de orden económico, político, científico, civil, administrativo, familiar y educativo.

Otra vertiente descarta tal dicotomía, al afirmar que mientras la prevención es un resultado, la sanción sólo constituye una medida alternativa para obtener ese resultado, y aunque algunas sanciones pudieran ser preventivas, otras podrían generar mayor delincuencia, y otras más, incluso no tener efecto alguno, ni preventivo ni criminogénico: lo mismo aplica para otras medidas preventivas distintas a la sanción penal. De este modo, la prevención de la delincuencia debería definirse por sus 
consecuencias potenciales, no por sus intenciones: o se reduce el número de delitos o el número de delincuentes; o se reduce el daño de los delitos o el número de víctimas; en términos más amplios, la prevención implica disminuir los factores de riesgo de delito e incrementar los factores de protección (Sherman et al., 1997).

Algunas visiones alternativas conciben las medidas de control como de prevención reactiva, puesto que no atienden las causas originarias de la criminalidad, mientras que la prevención proactiva apunta a las medidas de transformación social-estructural de largo plazo (Gutiérrez, 2015). También se ha enunciado esta dualidad como prevención desde dentro del sistema penal para las medidas de control, y prevención desde fuera para las medidas preventivas (Umaña, 2015). Así, es posible concluir, preliminarmente, que las medidas de prevención, opuestas o no a las medidas de control, son ajenas a la sanción penal.

México Evalúa (2014) define la prevención del delito como "acciones enfocadas a disminuir las amenazas, el riesgo y las oportunidades de que el delito ocurra mediante la identificación y eliminación de las causas, elementos de oportunidad y condiciones sociales que permiten que la delincuencia se desarrolle y fortalezca" (pp. 10-11). Estas acciones se pueden ubicar en tres distintas tipologías: en la primera, que obedece al grado de desarrollo del delito, la prevención puede ser primaria, si se basa en revertir condiciones socioeconómicas de la comunidad asociadas al delito; secundaria, si consiste en la intervención temprana de zonas o grupos potencialmente delictivos; y terciaria, si se orienta a evitar la reincidencia de quienes ya cometieron (o fueron víctimas de) un delito; en la segunda, si se clasifican las acciones según la estrategia operacional para prevenir el delito, la prevención puede ser situacional, si atiende los factores circunstanciales personales en la ocurrencia del delito; comunitaria, si encamina las acciones a la transformación de las condiciones sociales que propician la delincuencia; o de criminalidad, si se enfoca a la identificación y seguimiento de las carreras criminales de las personas; en la tercera, si se clasifican de acuerdo con la orientación estratégica, la prevención puede forjarse a través del desarrollo social, si remite a la intervención temprana en los factores de oportunidad y criminalidad, así como a las relaciones sociales y comunitarias, o a través del diseño ambiental, si se orienta al diseño de entornos no propicios para la criminalidad.

En resumen, toda política de prevención sigue la lógica de identificación de causas y factores asociados a la delincuencia, para entonces conducir acciones orientadas a reducir su probabilidad de ocurrencia. Ahora bien, ¿cuáles son estas causas y estos factores asociados? En la literatura predomina la concepción de la delincuencia como 
fenómeno multicausal; entre las principales explicaciones del origen de las conductas delictivas, destacan las teorías institucional, cultural, internacionalista, estructural, racional, psicoanalítica, de la modernización y ecológica.

La teoría institucional sustenta la criminalidad en las fallas en el Estado de Derecho y la corrupción de las instituciones de seguridad y justicia; en cuanto a la teoría cultural, afirma que la desintegración familiar y, en general, la descomposición del tejido social son factores asociados a la criminalidad; la teoría internacionalista, en contraste, apunta a factores globales de la criminalidad, como el narcotráfico y el terrorismo, lo cual provoca que estrategias locales y nacionales no logren contener eficazmente la delincuencia (Valdez, 2000).

La teoría estructural, por otro lado, señala que la delincuencia se produce por un ajuste en las estructuras socioeconómicas, de modo que, según Valdez (2000), en épocas de crisis suele registrarse un aumento en la criminalidad, lo cual, como bien advierte Merton (1938), no debe asociarse a la correlación entre pobreza y delincuencia, sino a una configuración social compuesta por pobreza, desigualdad de oportunidades y un sistema común compartido de símbolos de éxito, que lleva a un sector de la población a recurrir a medios ilícitos. Esta idea no sólo explica la relación de corto plazo entre desempleo cíclico y delitos patrimoniales, también impacta otras relaciones como desigualdad y narcoviolencia. ${ }^{5}$

La teoría racional prioriza el cálculo de costos y beneficios esperados del individuo, como factor determinante en su decisión de cometer o no un delito (Valdez, 2000). Bajo esta lógica utilitarista, un individuo decide si se involucra en actividades legales o ilegales que conducen al mismo resultado (por ejemplo, incrementar su patrimonio a través del trabajo o del robo), de manera continua, en el transcurso de su vida, evaluando los beneficios y costos en un escenario de incertidumbre (Ehrlich, 1974); así, la incidencia delictiva se encuentra en función no solo de la severidad de la pena, sino también de la probabilidad de ser capturado y el costo de oportunidad que representa obtener el beneficio de la actividad ilícita por medios lícitos (Becker, 1974).

La teoría psicoanalítica, en contraste, explica la criminalidad mediante factores patológicos que llevan a los individuos a conductas violentas o delictivas (Valdez, 2000); así, el acto criminal se asocia con determinados rasgos de personalidad que prevalecen en

${ }^{5}$ Por ejemplo, el estudio de Enamorado, López Calva, Rodríguez-Castelán, y Winkler (2016) demuestra cómo el incremento de un punto en el coeficiente de Gini, a nivel municipal, se traduce en un aumento aproximado del $36 \%$ en la tasa de homicidios relacionados con el narcotráfico por cada 100,000 habitantes, en el período 2007-2010, en México. 
quienes lo cometen, con ciertos trastornos psicopatológicos, o bien con motivaciones de carácter inconsciente (Aguilera Torrado, 2010).

La teoría de la modernización descansa en la separación temprana de los jóvenes de su hogar, sea por necesidad económica o por la ausencia de espacios de convivencia adecuados, lo cual genera condiciones propicias para que tomen la delincuencia como camino fácil para lograr sus aspiraciones (Valdez, 2000). Bajo esta perspectiva, las juventudes están sujetas a entornos caracterizados por la necesidad de expresiones de rebeldía, debido a carencias afectivas o a la ausencia de una figura paterna, a la búsqueda de una identidad propia (así sea negativa, a través del delito) y a las ansiedades propias de la adolescencia (Kvaraceus, 1964, pp. 38-52).

Otra visión explicativa de la delincuencia es la teoría ecológica del delito, la cual delinea a la ciudad como problema, en tanto los procesos de urbanización, industrialización, migración, y sus consecuentes transformaciones políticas y culturales provocan una desorganización social o comunitaria, potenciando la criminalidad en sujetos vulnerables, por su condición social, en zonas de deterioro urbano; específicamente, entre los jóvenes de zonas marginadas o en situación de pandillerismo o adicciones (Ayos, 2014).

Una vez expuestas de manera sucinta estas teorías, se evidencia el vínculo entre enfoques de prevención y teorías de la delincuencia. Como afirma Ayos (2014), toda política de prevención del delito se construye sobre la definición de qué es el delito y cuáles son sus causas y alternativas de solución. Así, cada enfoque de prevención encuentra su correspondencia en una o más teorías de la delincuencia, las cuales, al definir las causas del delito, delinean las posibles acciones preventivas. Esto resulta, por ejemplo, en la correspondencia entre la teoría racional y las medidas de prevención situacional y de diseño ambiental, orientadas a encarecer la comisión del delito, en el sentido de aumentar la probabilidad de captura; incluso existe correspondencia con algunas medidas de prevención social relacionadas con la mejora en los niveles de educación y empleo, al aumentar el costo de oportunidad de obtener beneficios por actividades ilícitas y disminuir, en cambio, el costo de oportunidad de acceder a ellos por actividades lícitas.

Otra correspondencia evidente se encuentra entre la teoría psicoanalítica y los enfoques de prevención psicosocial, de criminalidad, de reinserción y de prevención terciaria, los cuales se orientan a elementos psicológicos criminógenos en individuos que iniciaron una carrera criminal, o en aquellos en condiciones de riesgo, como adicciones o pandillerismo. La teoría ecológica, por otro lado, encuentra una correspondencia con los 
enfoques de prevención basados en la localidad, psicosocial y de prevención secundaria, ya que destaca la implementación de políticas focalizadas, basadas en una segmentación territorial e intervención multiagencial.

ESTRATEGIA METODOLÓGICA PARA EL DIAGNÓSTICO DE VIOLENCIA CRIMINAL Y EVALUACIÓN DE LA POLÍTICA DE PREVENCIÓN

En las secciones previas, se planteó cómo la política criminológica implica el ejercicio de la función punitiva del Estado, a través de las instituciones de seguridad y justicia (policías, fiscalías, juzgados penales y sistema penitenciario), pero también la ejecución de políticas de prevención que operan mediante enfoques sociales, comunitarios, situacionales y focalizados, a partir de distintas teorías que explican la comisión de delitos. Por tanto, se considera que el estudio de la seguridad pública y la violencia criminal en Acapulco requiere del análisis empírico, tanto del contexto en el que ocurre dicha violencia, como de las acciones de prevención implementadas para su atención.

En esta sección se expone la estrategia metodológica que permitió realizar un diagnóstico de la violencia criminal en Acapulco, y una evaluación del diseño de las acciones implementadas en el marco del PRONAPRED, en el período 2013-2018, al interior de cinco polígonos geográficos prioritarios del municipio.

Para comprender el contexto en el que se desenvuelve la violencia criminal fue necesario conocer la evolución de indicadores fundamentales de seguridad pública, así como el estado de las instituciones de seguridad y justicia. Para tal efecto, se utilizaron los datos abiertos de incidencia delictiva del Secretariado Ejecutivo del Sistema Nacional de Seguridad Pública, bases de datos sobre seguridad y justicia, a nivel municipal, del Instituto Nacional de Estadística, Geografía e Informática (INEGI), y diagnósticos de supervisión penitenciaria de la Comisión Nacional de los Derechos Humanos (CNDH), con el fin de recabar información sobre la evolución y estructura de la incidencia delictiva, las cargas de trabajo que enfrentan tanto la procuración como la impartición de justicia y el estado actual del sistema penitenciario.

También fue necesario recabar información sobre seguridad pública en los polígonos intervenidos por el PRONAPRED. Para tal efecto, en dos momentos del período estudiado se aplicó una encuesta; el primer levantamiento se realizó en marzo de 2016, con un muestreo aleatorio simple al interior de cada polígono, tomando como variable de referencia la proporción de hogares o personas que sufrieron un delito en los últimos 12 meses. El tamaño muestral resultante fue de $n=831$ encuestas aplicadas a mayores de 
edad en sus viviendas, distribuidas en los polígonos Petaquillas (168), Renacimiento (168), Zapata (167), Progreso (163) y Jardín (165). Los cálculos del muestreo utilizaron un nivel de confianza del $95 \%(z=1.96)$, un error máximo aceptado del $5 \%(e=0.05)$ y una proporción de $12.5 \%(p=0.125)$. Mediante un cuestionario, se obtuvo información sobre la ocurrencia de delitos, la percepción de inseguridad, y la modificación de actividades cotidianas por temor a ser víctimas de algún delito.

El segundo levantamiento se realizó en mayo de 2019, con un muestreo aleatorio simple para los cinco polígonos y con distribución proporcional de acuerdo con su peso relativo por tamaño de población, tomando como variable de referencia la proporción de hogares o personas que sufrieron un delito en los últimos 12 meses. El tamaño muestral resultante fue de $n=1,104$ encuestas aplicadas a mayores de edad en sus viviendas, distribuidas en los polígonos Petaquillas (175), Renacimiento (201), Zapata (184), Progreso (218) y Jardín (326). Para estos cálculos de muestreo se utilizaron un nivel de confianza del $95 \%(z=1.96)$, un error máximo aceptado de $1.95 \%(e=0.0195)$, y una proporción de $13.7 \%(p=0.137)$.

Para analizar las acciones de prevención efectuadas por el PRONAPRED, se recurrió a la metodología de evaluación de diseño. De acuerdo con el Consejo Nacional de Evaluación de la Política de Desarrollo Social (CONEVAL, 2016), esta metodología permite valorar la lógica interna de un programa en sus primeros años de implementación. Utilizando un análisis de gabinete de información proveniente de registros administrativos, documentación pública y evaluaciones externas, se evaluó la justificación del programa, su vinculación con otros planes, la población objetivo, mecanismos de atención, así como probables complementariedades o coincidencias con otros programas. Para evaluar el diseño de la política de prevención implementada en Acapulco, se revisaron los anexos únicos de coordinación y adhesión para el otorgamiento de apoyos a Guerrero, en el marco del PRONAPRED de 2013 a 2018, el diagnóstico participativo realizado por dicho programa en 2015 y las evaluaciones nacionales externas realizadas por México Evalúa en los años 2014 y 2015.

HALlazgos EMPÍRICOS DEL CONTEXTO DE VIOLENCIA CRIMINAL Y EVALUACIÓN DE LA POLÍTICA DE PREVENCIÓN

El primer indicador relevante del contexto de violencia y delincuencia en Acapulco es su incidencia delictiva. La Tabla 1 muestra una disminución gradual de la ocurrencia de 
delitos en los últimos años, encontrando la cifra mínima precisamente en 2018, con 11,762 presuntos delitos registrados. Este comportamiento se replica en las cifras desagregadas por tipo de delito, para robo, lesiones dolosas y delitos sexuales; sin embargo, la proporción de delitos de alto impacto ha aumentado en los últimos dos años, es decir, aunque se registra un menor número de delitos, en términos absolutos, la naturaleza de éstos, en términos relativos, corresponde a tipos penales más graves. No hay que olvidar, además, que la tendencia delictiva decreciente que reflejan estos datos no incluye la cifra negra, pues se basan en denuncias interpuestas ante los ministerios públicos.

Tabla 1. Evolución de la incidencia delictiva del fuero común en Acapulco

\begin{tabular}{lrrrrrrrr}
\hline & 2011 & 2012 & 2013 & 2014 & 2015 & 2016 & 2017 & 2018 \\
\hline Incidencia delictiva total $_{\text {Robo }}$ & 20,522 & 18,209 & 17,452 & 17,392 & 16,516 & 17,221 & 14,566 & 11,762 \\
Otros delitos patrimoniales $^{1}$ & 9,711 & 8,710 & 7,998 & 8,219 & 7,124 & 6,823 & 5,658 & 4,264 \\
Lesiones dolosas & 1,691 & 1,525 & 1,568 & 1,702 & 1,606 & 1,443 & 1,358 & 1,487 \\
Homicidios dolosos $^{2}$ & 1,382 & 1,313 & 1,224 & 1,335 & 1,206 & 1,294 & 1,300 & 971 \\
Delitos sexuales $^{3}$ & 1,008 & 1,170 & 883 & 590 & 902 & 933 & 842 & 853 \\
Secuestro $^{\text {Porcentaje de delitos de alto impacto }^{4}}$ & 233 & 209 & 233 & 221 & 254 & 199 & 202 & 170 \\
\hline
\end{tabular}

Fuente: Elaboración propia, con datos abiertos de incidencia delictiva del Secretariado Ejecutivo del Sistema Nacional de Seguridad Pública (presuntos delitos registrados en las averiguaciones previas o carpetas de investigación iniciadas); ${ }^{1}$ incluye extorsión, fraude, despojo, abuso de confianza y daño en propiedad ajena; ${ }^{2}$ incluye feminicidios; ${ }^{3}$ incluye violación simple, violación equiparada y abuso sexual; ${ }^{4}$ el porcentaje se calcula considerando lesiones dolosas, homicidios dolosos, delitos sexuales y secuestro, respecto a la incidencia delictiva total.

Otros indicadores relacionados con la carga de trabajo que enfrentan las instituciones de seguridad y justicia, no necesariamente muestran una actividad delictiva a la baja. Por ejemplo, en el período 2007-2012 (véase Gráfica 1), el número de procesados en Acapulco por el Ministerio Público Federal fue en aumento, mientras que los procesados del fuero común disminuyeron hasta 2011, para un posterior repunte en 2012. Según cifras del Sistema Estatal y Municipal de Bases de Datos del INEGI, en 2007 Acapulco contaba con 27 agencias del Ministerio Público del fuero común y una agencia del fuero federal, con 163 y 18 agentes, respectivamente; para 2012, sólo operaban 14 agencias del fuero común y una del fuero federal, con 139 y 15 agentes, respectivamente; todo ello muestra cómo las cargas de trabajo se han visto reflejadas en el número de agentes del Ministerio Público en el fuero común, pero no en el fuero federal, pues a pesar del aumento del número de procesados, la cantidad de agentes ha disminuido. 
Gráfica 1. Número de procesados en Acapulco

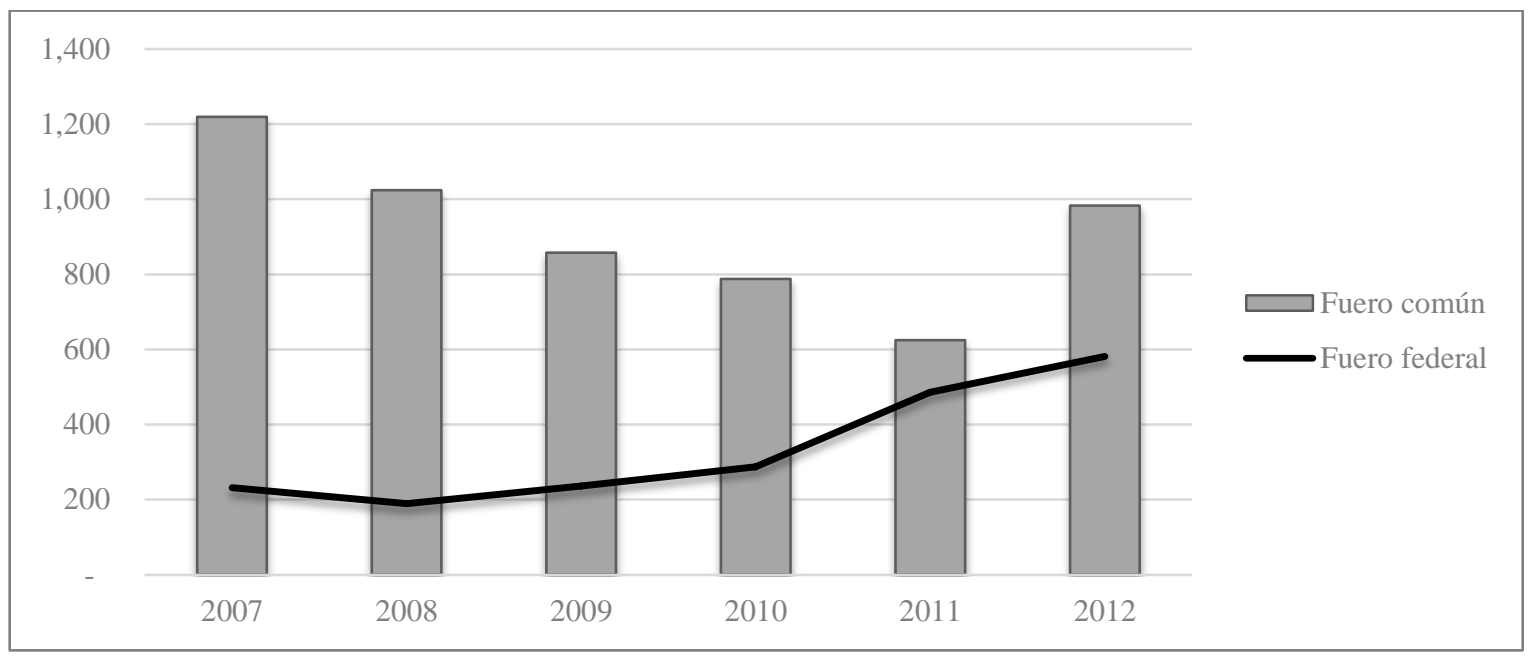

Fuente: Elaboración propia, con datos del Sistema Estatal y Municipal de Bases de Datos del INEGI.

La gráfica 2, por otro lado, muestra la carga de trabajo para la función jurisdiccional, al exponer el número de sentenciados en Acapulco. En el fuero común, a pesar de las fluctuaciones intermedias, los niveles finales son similares a los iniciales, mientras que en el fuero federal, de nuevo, la tendencia es creciente. Desafortunadamente, las series de datos respecto al número de procesados y sentenciados a nivel municipal no han sido actualizadas por el INEGI, de ahí que las últimas mediciones disponibles sean de 2012. Al respecto, si bien la información disponible es limitada, al menos permite vislumbrar que la implementación del PRONAPRED, iniciada en 2013, se enfrentó con una clara tendencia creciente de delitos del fuero federal en Acapulco, mientras que los delitos del fuero común contaban con una ligera tendencia a la baja, o al menos constante.

En Guerrero, en cambio, se cuenta con información actualizada, gracias al Censo Nacional de Impartición de Justicia Estatal que realiza anualmente el INEGI. Según esta fuente, a las entidades jurisdiccionales del Estado ingresaron, en 2013, 6,762 causas penales del fuero común, que se sumaron a las 6,934 que se encontraban pendientes de años anteriores, logrando concluir en dicho año solamente 3,801, lo cual representaría una tasa de resolución del 27.7 \%. Para 2018 ingresaron 1,107 causas penales, se encontraban pendientes 7,941 y se concluyeron 709, con lo cual la tasa de resolución se ubicaba en $7.8 \%$. 
Gráfica 2. Número de sentenciados en Acapulco

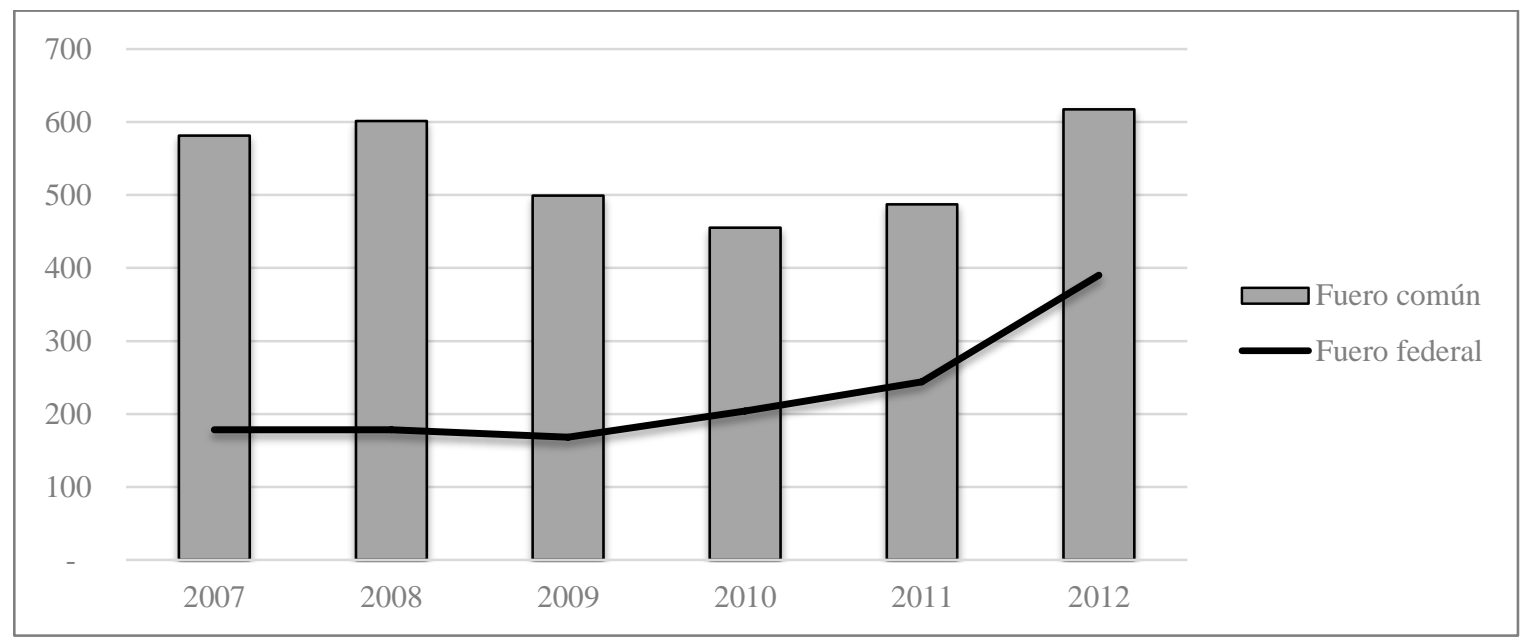

Fuente: Elaboración propia, con datos del Sistema Estatal y Municipal de Bases de Datos del INEGI.

Respecto al sistema penitenciario (Gráfica 3), en el Centro Regional de Reinserción Social de Acapulco, entre 2013 y 2016, la tasa de sobrepoblación llegó a rebasar el 50 $\%$, para disminuir casi por completo en los años posteriores; en 2014 alcanzó un máximo de sobrepoblación, al contar con una capacidad instalada para 1,650 internos, y una población de 2,571. Si bien se logró reducir la brecha entre capacidad instalada y población penitenciaria (para 2019 la tasa de sobrepoblación era inferior al $1 \%$ ), el estado de Guerrero se encuentra en penúltimo lugar en la evaluación diagnóstica que la $\mathrm{CNDH}$ realiza a los centros penitenciarios de todo el país (véase Gráfica 4). Tal diagnóstico promedia los puntajes (en una escala del 0 al 10) en rubros relacionados con garantizar la integridad física y moral del interno, una estancia digna, condiciones de gobernabilidad del centro penitenciario, así como condiciones para la reinserción social del interno y el estado de grupos de internos con requerimientos específicos. 


\section{Gráfica 3. Población penitenciaria en Acapulco}

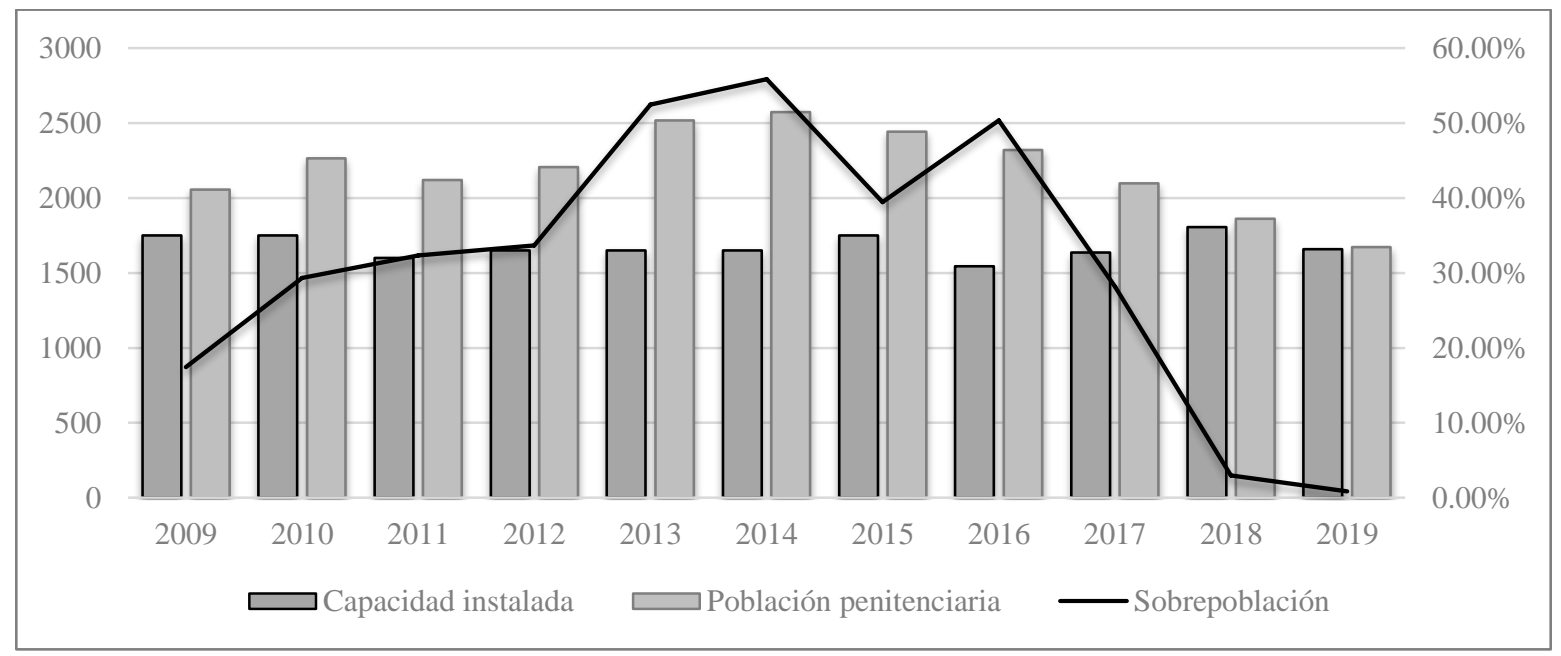

Fuente: Elaboración propia, con datos del Diagnóstico Nacional de Supervisión Penitenciaria de la CNDH, 2009-2019

\section{Gráfica 4. Diagnóstico de CERESOS estatales 2019}

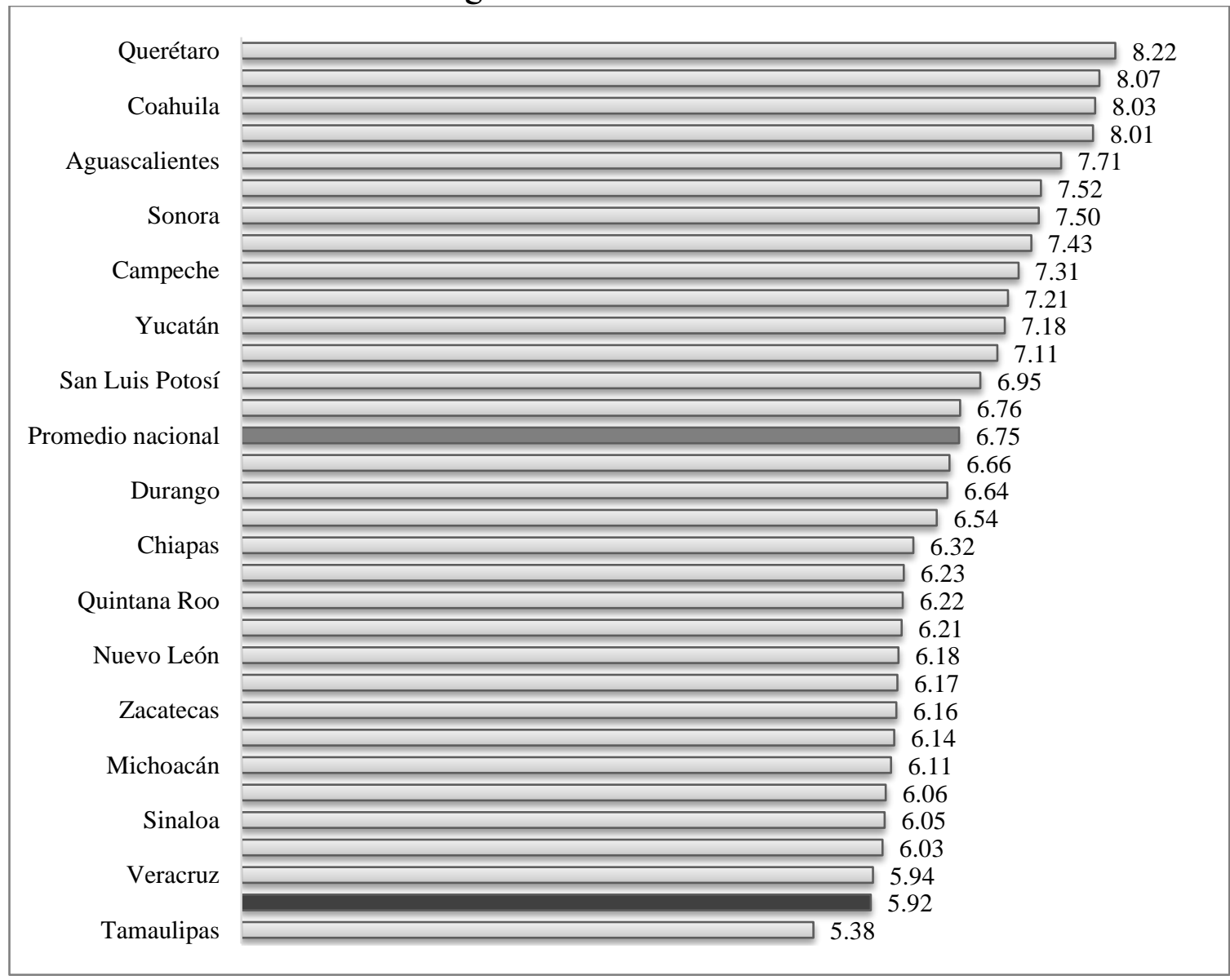

Fuente: Elaboración propia, con datos del Diagnóstico Nacional de Supervisión Penitenciaria de la CNDH, 2019; el puntaje específico del Centro Regional de Reinserción Social de Acapulco fue de 6.04. 
Los datos presentados muestran un panorama desalentador para la política criminal, desde la perspectiva de las instituciones de seguridad y justicia. Si bien las policías pudieron haber enfrentado una incidencia delictiva aparentemente decreciente, los datos de procuración e impartición de justicia son claros respecto a la tendencia incremental de los delitos del fuero federal, además de las deficientes capacidades para la reinserción social del centro penitenciario del municipio.

Los indicadores anteriores permiten contextualizar los hallazgos obtenidos en las encuestas aplicadas en 2016 y 2019, respecto a las condiciones de seguridad ciudadana de los polígonos intervenidos por el PRONAPRED. En cuanto a la incidencia delictiva, fue medida en términos directos e indirectos. La Tabla 2 muestra el porcentaje de personas que en cada polígono refirió haber sido víctima de algún delito, además de señalar si algún familiar, amigo o vecino también lo fue.

Desde la perspectiva de la victimización directa, los polígonos con mayor ocurrencia de delitos en 2016 fueron Jardín y Zapata, mientras que en 2019 fueron Zapata y Progreso; no obstante, en el agregado se observa una reducción de la incidencia delictiva directa de casi cuatro puntos porcentuales entre ambas mediciones. Si se considera la victimización indirecta, también se observan reducciones considerables en la incidencia delictiva de familiares, amigos y vecinos.

Según las encuestas realizadas, el delito más frecuente en todos los polígonos (durante ambos años) fue el robo o asalto; también se encontró que, entre los encuestados de 2016, solamente el $14 \%$ de quienes fueron víctimas de algún delito presentó su denuncia ante el Ministerio Público, mientras que en 2019 esa cifra subió al 24 \%. En México, según la Encuesta Nacional de Victimización y Percepción sobre Seguridad Pública (ENVIPE) de 2019, el delito de mayor ocurrencia fue también el robo o asalto, pero la proporción de quienes presentaron una denuncia fue de apenas $10.6 \%$.

Tabla 2. Incidencia delictiva por polígono

(En los últimos 12 meses, ¿fue víctima de algún delito...?)

\begin{tabular}{lrrrrrrrr}
\hline & \multicolumn{2}{c}{ Usted } & \multicolumn{2}{c}{ Un familiar } & \multicolumn{2}{c}{ Un amigo } & \multicolumn{2}{c}{ Un vecino } \\
Año & 2016 & 2019 & 2016 & 2019 & 2016 & 2019 & 2016 & 2019 \\
\hline Petaquillas & 9.0 & 5.0 & 25.4 & 19.4 & 27.9 & 31.9 & 28.1 & 23.6 \\
Zapata & 14.5 & 15.8 & 15.1 & 23.3 & 16.2 & 22.6 & 22.4 & 24.3 \\
Renacimiento & 13.7 & 10.6 & 37.6 & 13.6 & 34.5 & 13.5 & 40.5 & 11.2 \\
Progreso & 11.1 & 11.9 & 38.7 & 18.6 & 48.0 & 19.6 & 41.9 & 11.2 \\
Jardín & 20.7 & 7.9 & 28.1 & 8.9 & 41.4 & 13.6 & 45.5 & 9.3 \\
\hline General & $\mathbf{1 3 . 5}$ & $\mathbf{9 . 6}$ & $\mathbf{2 9 . 2}$ & $\mathbf{1 5 . 1}$ & $\mathbf{3 4 . 1}$ & $\mathbf{1 8 . 9}$ & $\mathbf{3 5 . 8}$ & $\mathbf{1 4 . 1}$ \\
\hline
\end{tabular}

Fuente: elaboración propia, con datos del trabajo de campo (datos porcentuales) 
En la encuesta aplicada en 2016, la percepción de inseguridad de los habitantes de los polígonos fue medida en una escala del 1 al 10, donde 1 significaba nada seguro y 10 muy seguro, cuestionando la percepción en distintos entornos cotidianos. De aquellos que fueron mencionados, en donde se sentían más inseguros era en los cajeros automáticos y el transporte público, mientras que los más seguros fueron su trabajo o escuela y el interior de su casa.

Tabla 3. Percepción de inseguridad 2016

\begin{tabular}{lrr}
\hline En una escala del 1 al 10, ¿qué tan seguro se siente... & Media & Desviación estándar \\
\hline .. en el interior de su casa? & 7.70 & 2.84 \\
... en su trabajo/ escuela? & 6.46 & 2.95 \\
.. en la colonia donde vive? & 5.18 & 3.01 \\
.. en Acapulco? & 4.40 & 2.83 \\
$\ldots$. en el transporte público? & 3.97 & 2.50 \\
$\ldots$. en el cajero automático? & 3.37 & 2.42 \\
.. en tiendas o comercios? & 5.09 & 2.65 \\
.. en la zona turística? & 5.44 & 2.82 \\
\hline Seguridad promedio & 5.20 & 1.81 \\
\hline
\end{tabular}

Fuente: Elaboración propia, con datos de trabajo de campo.

En 2019, en cambio, sólo se preguntó si se sentía seguro o inseguro en distintos entornos cotidianos, algunos coincidentes con los que se preguntaron en 2016, pero no directamente comparables por contar con distinto formato de respuesta. De nuevo, los lugares donde los encuestados se sentían más inseguros fueron el cajero automático y el transporte público, mientras que los más seguros fueron su casa y su trabajo. A nivel nacional, los datos de la ENVIPE 2019 coinciden, al señalar el cajero automático en la vía pública, el transporte público y el banco como los lugares con mayor percepción de inseguridad, mientras que los más seguros fueron la casa y el trabajo.

Tabla 4. Percepción de inseguridad 2019

\begin{tabular}{|c|c|c|}
\hline En términos de delincuencia, dígame si se siente SEGURO o INSEGURO en... & Seguro & Inseguro \\
\hline$\ldots$ su casa & 76.8 & 23.2 \\
\hline$\ldots$ su trabajo & 51.1 & 48.9 \\
\hline ... la calle & 19.8 & 80.2 \\
\hline ... la escuela & 30.7 & 69.3 \\
\hline ... el mercado & 19.7 & 80.3 \\
\hline$\ldots$ el centro comercial & 26.7 & 73.3 \\
\hline ... el banco & 17.2 & 82.8 \\
\hline ... el cajero automático localizado en la vía pública & 13.4 & 86.6 \\
\hline ... el transporte público & 16.4 & 83.6 \\
\hline ... en un automóvil particular & 27.4 & 72.6 \\
\hline ... la carretera & 17.5 & 82.5 \\
\hline ... el parque o centro recreativo & 19.9 & 80.1 \\
\hline ... en esta colonia & 50.8 & 49.2 \\
\hline ... en Acapulco & 27.9 & 72.1 \\
\hline ... en Guerrero & 25.0 & 75.0 \\
\hline
\end{tabular}

Fuente: Elaboración propia, con datos de trabajo de campo (datos porcentuales). 
Si bien las mediciones respecto a la percepción de inseguridad de los ciudadanos no provienen de reactivos equivalentes, toda vez que se usaron distintas escalas de medición y entornos de percepción, es un resultado interesante que el ordenamiento haya replicado en términos generales los entornos más seguros e inseguros, pues la incidencia delictiva directa e indirecta, como ya se demostró, tuvo una reducción considerable. Por tanto, podríamos concluir, preliminarmente, que la percepción de inseguridad no parece estar correlacionada con la ocurrencia de delitos, ya sea de manera directa o indirecta, en alguna persona cercana.

A pesar de lo anterior, tanto la incidencia delictiva como la percepción de inseguridad pueden incidir en las actividades cotidianas de las personas, debido al temor de ser víctima de un delito. En la Tabla 5 se muestra el porcentaje de personas que dejaron de hacer ciertas actividades por temor a ser víctimas de algún delito; las más recurrentes, tanto en 2016 como en 2019, fueron dejar de usar joyas, dejar de salir de noche y dejar salir solos a menores que viven en el hogar. Estos resultados coinciden con la tendencia nacional, pues en la ENVIPE 2019 se estima que las principales actividades modificadas por temor a sufrir un delito en México fueron permitir que los menores de edad salieran (71 \%), usar joyas (60.9\%), y salir de noche (53.4\%).

Hay que destacar, también, que en siete actividades aumentó el porcentaje de personas que dejaron de hacerlas por temor a sufrir un delito; estas actividades, si se analizan con detenimiento, se asocian a la intención de reducir el tiempo que se pasa fuera del hogar (evadiendo salir, por temor, a algún lugar, o evitando traslados en transporte público o carretera).

Por otro lado, aquellas actividades donde disminuyó el porcentaje de personas que dejaron de hacerlas, se relacionan con el temor de ser víctima de algún robo o asalto, resultado un tanto contra-intuitivo, pues estos delitos fueron los de mayor prevalencia en las encuestas de ambos años; aunque, si se vuelve a consultar la Tabla 1, el delito de robo disminuyó en un 37.5 \% en el período 2016-2018, situación que podría explicar esta disminución del temor a usar joyas, salir de noche, llevar dinero en efectivo o tarjetas bancarias, o usar el teléfono celular en público. 
Tabla 5. Modificación de actividades cotidianas por temor a ser víctimas de un delito

\begin{tabular}{|c|c|c|}
\hline $\begin{array}{l}\text { En los últimos } 12 \text { meses, por temor a ser víctima de un delito, } \\
\text { usted dejó de... }\end{array}$ & 2016 & 2019 \\
\hline ... ir al trabajo o a la escuela & 12.9 & 24.4 \\
\hline$\ldots$ ir al cine & 23.5 & 32.8 \\
\hline ... salir a comer o a cenar & 35.1 & 37.0 \\
\hline$\ldots$ visitar amigos o familiares & 25.5 & 40.6 \\
\hline ... llevar dinero en efectivo & 51.0 & 38.1 \\
\hline ... usar joyas & 70.9 & 54.4 \\
\hline ... salir de noche & 67.5 & 58.9 \\
\hline ... dejar salir solos a menores que viven en el hogar & 54.2 & 56.6 \\
\hline ... usar transporte público & 22.1 & 31.3 \\
\hline$\ldots$ viajar en carretera & 24.5 & 33.7 \\
\hline ... llevar tarjetas de crédito o débito & 43.9 & 36.8 \\
\hline ... usar su celular en la vía pública & 45.4 & 39.2 \\
\hline
\end{tabular}

Fuente: Elaboración propia, con datos de trabajo de campo (datos porcentuales).

Además de modificar patrones de comportamiento cotidiano, las personas pueden implementar medidas de autoprotección para evitar ser víctimas de algún delito o simplemente para sentirse más seguras. Entre las acciones preguntadas en las encuestas, las respuestas más frecuentes fueron reforzar y proteger los accesos a las viviendas, mediante cerraduras, protectores, muros, cercas o incluso con la adquisición de un perro guardián. Algunas acciones con incrementos relativos entre 2016 y 2019 fueron la contratación de seguros, los sistemas de alarmas y videovigilancia, así como la adquisición de armas de fuego. A nivel nacional, de acuerdo con los datos de la ENVIPE 2019, las medidas de autoprotección predominantes también refieren el uso de cerraduras o candados (31.3\%), cambio de puertas o ventanas (25.9\%) y colocación de rejas o bardas $(17.9 \%)$.

Tabla 6. Medidas de autoprotección por temor a ser víctimas de un delito

\begin{tabular}{lrr}
\hline En los últimos 12 meses, por temor a ser víctima de un delito, & 2016 \\
¿usted ... & 3.3 & 5.5 \\
\hline ... contrató algún seguro? & 24.6 & 10.3 \\
... adquirió un perro guardián para el hogar? & 29.0 & 24.7 \\
... reforzó cerraduras en puertas o colocó protectores en ventanas? & 9.4 & 15.2 \\
... levantó muros o cercas en su casa? & 2.3 & 4.6 \\
... instaló alarmas o sistemas de video vigilancia? & .9 & 3.8 \\
... adquirió un arma de fuego? & 5.4 & 4.1 \\
\hline
\end{tabular}

Fuente: Elaboración propia, con datos de trabajo de campo (datos porcentuales).

Los datos anteriores muestran un panorama claro respecto a los niveles de incidencia delictiva, percepción de inseguridad, temor al delito y medidas de autoprotección de los 
habitantes de los polígonos intervenidos por el PRONAPRED. A continuación, se presenta una revisión detallada de las acciones del programa, con el fin de evaluar cómo fueron atendidos estos polígonos, y vislumbrar si efectivamente las acciones programadas tenían el potencial de disminuir los factores de riesgo del delito.

Las acciones de prevención implementadas, de 2013 a 2018, en este municipio se desarrollaron en cinco polígonos de atención prioritaria: Petaquillas (7,627 hab.), Renacimiento (10,665 hab.), Zapata (10,458), Progreso (9,963 hab.) y Jardín (16,844 hab.). En la Tabla 7 se muestra que dichos polígonos recibieron recursos durante cuatro años continuos; sin embargo, en 2017, el subsidio fue suspendido debido a los recortes presupuestales federales, y en 2018 fue reactivado con una suma bastante disminuida, tanto que solamente se canalizaron recursos al polígono Progreso.

Tabla 7. Montos que asignó PRONAPRED por polígono

\begin{tabular}{|c|c|c|c|c|c|c|}
\hline & 2013 & 2014 & 2015 & 2016 & 2018 & Total \\
\hline Petaquillas & $17,061,887$ & $10,233,147$ & $18,400,813$ & $11,405,801$ & & $57,101,648$ \\
\hline Renacimiento & $18,061,887$ & $14,006,507$ & $12,643,304$ & $14,287,274$ & & $58,998,972$ \\
\hline Zapata & $21,205,038$ & $16,437,537$ & $15,612,494$ & $11,405,801$ & & $64,660,870$ \\
\hline Progreso & $19,261,887$ & $21,876,728$ & $27,231,458$ & $11,405,801$ & $4,909,817$ & $84,685,691$ \\
\hline Jardín & $23,561,887$ & $12,245,498$ & $12,620,088$ & $14,287,274$ & & $62,714,747$ \\
\hline Colosio/Coloso & & $16,740,186$ & & & & $16,740,186$ \\
\hline Fuera de polígonos & & $3,560,490$ & $2,228,713$ & $4,060,669$ & & $9,849,872$ \\
\hline Total & $99,152,586$ & $95,100,093$ & $88,736,870$ & $66,852,620$ & $4,909,817$ & $354,751,986$ \\
\hline
\end{tabular}

Fuente: Elaboración propia, con datos del Anexo Único de Coordinación y Adhesión para el otorgamiento de apoyos a Guerrero en el marco del PRONAPRED, en 2013 a 2016 y 2018 (cifras reales, deflactadas con el Índice Nacional de Precios al Consumidor de enero de 2013).

En el cuadro anterior, destacan algunas evidencias de falta de planeación y asignación racional de los recursos; por ejemplo, en 2014 se incorporaron dos polígonos a los cuales no se les dio seguimiento, por lo que las acciones implementadas quedaron aisladas de los posibles beneficios de su continuidad; por otro lado, en 2016 la asignación de recursos fue sospechosamente parecida entre Petaquillas, Zapata y Progreso, con un monto aproximado de 11.4 millones de pesos por polígono, mientras que en Renacimiento y Jardín la cifra fue de 14.3 millones de pesos para cada uno. ¿Cómo es que coinciden los montos por polígono, si cada uno de ellos tiene un tamaño de población diferente, con distintos factores de riesgo que debieron ser identificados en los diagnósticos participativos del año anterior? 
Esta desproporción es más evidente si se expresa el financiamiento recibido por habitante; bajo este criterio, en 2016 el polígono con menor recurso fue Jardín, con $\$ 848$ por habitante, seguido de Zapata, con $\$ 1,091$; Progreso, con $\$ 1,145$; Renacimiento, con $\$ 1,340 ; y$, finalmente, Petaquillas, con $\$ 1,495$. Contradictoriamente, en 2016 el polígono que recibió menor recurso per cápita (Jardín) fue el de mayor incidencia delictiva, mientras que quien recibió más (Petaquillas) tenía la incidencia delictiva más baja. Finalmente, si los recursos de 2018, cuando fue reactivado el PRONAPRED, se hubieran destinado al polígono con mayor incidencia delictiva según la encuesta de 2019, le hubiesen correspondido a Zapata y no a Progreso.

Más allá de su distribución, los recursos asignados fueron destinados a determinadas actividades que se traducían en diversos proyectos y programas orientados a la prevención desde la perspectiva social, comunitaria, situacional y focalizada. Hablando concretamente de lo implementado en el año 2013, algunos proyectos consistían en verdaderas estrategias integrales de prevención, centradas en alguna temática, por lo que las actividades que los conformaban requerían a su vez de un conjunto de acciones complejas, cuya implementación, por otro lado, no se detallaba; por ejemplo, el proyecto "Jóvenes en movimiento" se componía de actividades comunitarias, culturales, deportivas y de capacitación productiva, cuyo diseño no se explicaba detalladamente, quedando así a discrecionalidad del implementador. Otros proyectos, en cambio, eran más bien acciones concretas, por lo que las actividades que los conformaban representaban en realidad los pasos de ejecución de dicha acción; por ejemplo, el proyecto "Rehabilitación de albergue temporal" contemplaba las actividades de licitación de la obra, su ejecución y la contratación de especialistas para brindar la atención en el albergue.

Lo anterior refleja una falta de coherencia interna en el diseño del programa en su año inicial, pues lo clasificado como proyecto o actividad no es homogéneo. Otras falencias de diseño recaen en la categorización errónea de enfoques de prevención de los proyectos. En algunos casos, proyectos con una orientación de prevención claramente comunitaria eran clasificados como de prevención social (como el desarrollo de diagnósticos participativos), o bien proyectos explícitamente referidos como de prevención situacional (como la movilidad segura para la prevención situacional) eran clasificados como de prevención social y comunitaria.

En general, el PRONAPRED fue un programa fuertemente orientado a juventudes y urbanismo social en su año inicial, soslayando en cambio el planteamiento de actividades orientadas a mujeres y cultura de paz. Sin embargo, a partir de 2014, el diseño mejora, al 
anclar cada línea de acción a una estrategia que, a su vez, abona a un objetivo concreto. Con esta nueva estructura, el desbalance entre objetivos es menos marcado, aunque predominan ligeramente las acciones orientadas a grupos de atención prioritaria, por la cantidad de grupos que contempla (niños, jóvenes, mujeres, y población penitenciaria).

Además, se introduce un objetivo relativo a la mejora de las capacidades institucionales de los tres órdenes de gobierno en materia de prevención; sin embargo, las líneas de acción de este objetivo se encuentran completamente desvinculadas de la participación de la ciudadanía y los actores sociales en materia de prevención. En otras palabras, mientras se pugnaba por la construcción de capacidades ciudadanas en materia de diagnósticos, evaluación de programas, así como la conformación y capacitación de redes de prevención, las capacidades institucionales que se pretendían formar en los gobiernos parecían ser completamente independientes.

Por lo anterior, no había garantía de que, por ejemplo, los resultados de los diagnósticos elaborados fueran considerados por las autoridades. Esta desvinculación se agrava al observar que, durante los primeros cuatro años de operación del programa, se proyectaron 29 acciones relacionadas con diagnósticos comunitarios o participativos, con un presupuesto acumulado de 10.7 millones de pesos.

Analizando de manera conjunta las actividades y líneas de acción del PRONAPRED durante sus años de funcionamiento, es posible hacer los siguientes señalamientos: 1) el diseño del programa considera ciertas acciones que no tienen una relación clara con la prevención de la violencia y la delincuencia; 2) otras tantas están más cerca de cumplir funciones de entretenimiento que de prevención; 3) algunas acciones sí guardan una relación evidente con la prevención de la violencia y la delincuencia, pero su impacto resultaría difícil de medir; 4) otras se proponen para que sean utilizadas como insumo de nuevas acciones, pero no existen elementos que apunten a pensar que fueron tomadas en cuenta; y 5) acciones que, independientemente de estar relacionadas o no con la prevención, le corresponden a instancias ajenas a esta materia.

Cualquier actividad o línea de acción propuesta por el PRONAPRED puede ubicarse en alguno de los señalamientos anteriores. En el primero, correspondiente a acciones que difícilmente puede justificarse que tengan alguna función de prevención de violencia y delincuencia, pueden ubicarse la entrega de lentes, la entrega de auxiliares auditivos y la creación de huertos comunitarios. Estas mismas acciones ya habían sido criticadas a nivel nacional por parte de México Evalúa (2015), durante la evaluación del segundo año de operación del PRONAPRED, señalando una lógica de prevención cuestionable. Sin 
embargo, en el 2016, los huertos comunitarios llegaron a ser la única medida orientada a la reducción de factores de riesgo de violencia contra las mujeres en Acapulco.

Sobre el segundo señalamiento, relativo a acciones que están más cerca del entretenimiento que de la prevención, se puede mencionar la realización de conciertos musicales gratuitos, la promoción de artistas locales, funciones de cine, teatro y cuentacuentos; eventos deportivos, creación de bandas de música popular y la realización de verbenas populares. Aunque cualquiera de estas acciones de entretenimiento pudiera justificarse como preventiva, bajo el argumento de que fue realizada con actividades de acompañamiento relacionadas con la prevención, en términos de eficiencia es cuestionable que se le destinen recursos, en vez de canalizarlos a otras actividades con un vínculo más evidente y directo. Además, la prevención de la violencia y la delincuencia se define por su efecto potencial, no por su intención; así, el realizar una actividad de entretenimiento con la intención de promover la prevención del delito, no la vuelve preventiva.

En cuanto al tercer señalamiento, sobre aquellas acciones que, si bien se relacionan directamente con la prevención, su impacto difícilmente pudiera medirse, ahí se pueden ubicar las campañas de comunicación sobre temáticas diversas, como la cultura de la legalidad, las violencias (infantil, escolar, familiar, en el noviazgo), la educación sexual, el alcoholismo y las adicciones; esta dificultad para la medición de su impacto también fue señalada, a nivel nacional, por México Evalúa (2015).

Respecto al cuarto señalamiento, referente a las acciones que se realizan para delinear otras acciones, pero que no existe evidencia de que sean tomadas en cuenta, se pueden mencionar los diagnósticos participativos, las consultas ciudadanas para evaluar proyectos de prevención y los estudios sobre penas alternativas. En cuanto a los primeros es posible destacar que, aunque el diagnóstico participativo de 2015 identificaba explícitamente factores de riesgo diferenciados en cada polígono, las acciones programadas en 2016 fueron prácticamente las mismas en todos los polígonos, al igual que en 2014. Sobre el estudio de penas alternativas, destaca que éste se programó en 2015 con un presupuesto total de casi un millón de pesos reales, divididos en cinco partes iguales, para su realización en cada uno de los polígonos; estudio del cual se esperaría que emergieran propuestas focalizadas en la materia para el siguiente año; empero, en 2016 no fue programada una sola acción, en ninguno de los polígonos, orientada a la población interna en el sistema penitenciario.

Finalmente, se ha señalado la prevalencia de acciones que corresponden a instancias ajenas a la prevención de la violencia y la delincuencia, como entrega de becas, 
regularización escolar, apoyo a iniciativas productivas, capacitación para el trabajo, atención a víctimas, y la construcción, equipamiento y rehabilitación de espacios culturales, deportivos y comunitarios. Aunque todas estas acciones pueden asociarse con la prevención social y comunitaria, en teoría no debieran depender de la existencia de programas federales, al resultar competencia de las autoridades municipales o estatales en sus áreas de educación, desarrollo económico, procuración de justicia, cultura y deporte.

Sin embargo, no todas las acciones planteadas en el PRONAPRED caben dentro de estos señalamientos. Algunas de ellas, en efecto, cuentan con un alto potencial de prevención de violencia y delincuencia. Al dejar de lado las acciones antes cuestionadas, quedan cuatro conjuntos relevantes: 1) acciones focalizadas a grupos específicos; 2) acciones de prevención situacional; 3) actividades formativas en materias especializadas; y 4) acciones para la promoción de capacidades institucionales. En el primer conjunto, se destacan las acciones orientadas a la atención de grupos específicos con potencial de ser victimarios o víctimas de violencia y delincuencia en los polígonos de intervención, como lo son jóvenes, consumidores problemáticos, pandillas, agresores, así como la población penitenciaria y sus familias. Respecto al segundo grupo, las acciones de prevención situacional contemplan la recuperación de espacios públicos, la promoción de una movilidad segura e integral y la mejora de la imagen urbana de las zonas delincuenciales. En el tercer grupo, sobresalen aquellas actividades formativas o de capacitación en materias especializadas, como la prevención de violencia y delincuencia, la educación para la paz en el entorno escolar, la desnaturalización de las violencias, el respeto a los derechos de los niños, la parentalidad positiva, nuevas masculinidades y equidad de género. Finalmente, en el cuarto grupo destacan las acciones para institucionalizar, en los tres órdenes de gobierno, la prevención de la violencia y la delincuencia, de manera coordinada, sistematizada y tecnificada, en cuanto a la realización de diagnósticos, diseño e implementación de políticas públicas en la materia, así como su posterior evaluación y rediseño.

\section{CONCLUSIONES}

Las condiciones de seguridad ciudadana y violencia criminal en Acapulco representan un problema que está lejos de ser resuelto. La evolución del fenómeno ha posicionado al municipio como uno de los más violentos de México y del mundo. Ante este reto, la postura adoptada por el Estado fue la de prevenir el delito de manera proactiva, en complementariedad con una política criminal reactiva. 
Como parte de la prevención proactiva, se implementaron acciones en el ámbito público, pero ajenas a la sanción penal, orientadas a la reducción de factores de riesgo y promoción de factores de protección, con el fin último de disminuir la probabilidad de actos de violencia y delincuencia, desde los enfoques social, comunitario, situacional y focalizado. Sin embargo, los esfuerzos de prevención proactiva no pueden disociarse de la política criminal reactiva, pues si bien la primera opera en un espacio ajeno de la segunda (el sistema de justicia penal), el concebirlos como sustitutivos, en vez de complementarios, puede llevar al colapso de ambos. En este sentido, las instituciones de seguridad y justicia son fundamentales en la política criminal, y enfrentan simultáneamente retos de operación acorde con las nuevas disposiciones del Sistema de Justicia Penal Acusatorio y de legitimidad, ante la sociedad, por sus resultados.

La prevención proactiva conduce a identificar los orígenes, la naturaleza y las causas de la violencia y la delincuencia, con el fin último de atender los factores de riesgo y promover factores de protección. En este sentido, las teorías delincuenciales refieren la existencia de factores tan variados como las fallas del estado de derecho y la corrupción, la desintegración familiar y la descomposición del tejido social; problemas globales como el narcotráfico, la desigualdad económica y la pobreza; las conductas patológicas de naturaleza violenta o delincuencial, la ausencia de espacios comunitarios de sana convivencia, la personalidad vulnerable de los jóvenes o los procesos desordenados de urbanización, migración e industrialización.

En vista de lo anterior, una política de prevención integral invita a operar desde diversos frentes. No obstante, el hecho de que la prevención deba ser integral no implica que no tenga que ser eficiente; por tanto, no deberá atender todos los factores de riesgo teóricamente posibles, sino sólo aquellos que destaquen en un ejercicio previo de diagnóstico. En este sentido, resulta indispensable evaluar si las acciones del PRONAPRED mejoraron las condiciones de seguridad ciudadana de la población, en términos de incidencia delictiva y percepción de seguridad, y, de ser así, cuáles fueron los factores de riesgo y protección que generaron un mayor impacto.

La evaluación de diseño del PRONAPRED apunta a que la distribución de los recursos no se realizó mediante criterios racionales y objetivos, en función de la población de los polígonos o de los factores de riesgo de estos últimos. ${ }^{6}$ Tal arbitrariedad sirvió, en ocasiones, para concentrar el recurso en ciertos polígonos o acciones

\footnotetext{
${ }^{6}$ Resulta indispensable evaluar, incluso, la pertinencia de la estrategia de focalización geográfica a través de polígonos y, de ser necesario, replantearla.
} 
particulares, y otras tantas para distribuir los montos por igual entre cada polígono o acción.

Más allá de la distribución arbitraria de recursos, algunas de las acciones patrocinadas no tenían una relación clara con la prevención de violencia y la delincuencia; aquellas que lo tenían estaban más cerca de cumplir una función de entretenimiento que de prevención; otras tenían una relación clara de prevención y cercanas a cumplir su función, pero con impactos difíciles de medir; y algunas más, que debieron haber servido para conducir otras acciones, en realidad no fueron tomadas en cuenta. Están también las acciones asistencialistas que ocupan el espacio que deberían llenar instancias ajenas a la prevención: diseñar e implementar las políticas públicas que les corresponden a otros en materia de educación, salud, cultura o deporte, no es prevenir, sino subsidiar la ineficacia de su desempeño.

Fuera de estos casos, las acciones de prevención rescatables del diseño del PRONAPRED implican la atención focalizada a grupos vulnerables (tanto por delinquir como por ser víctimas), la prevención situacional, la construcción de capacidades ciudadanas en materias específicas de prevención y la promoción de capacidades en las instituciones encargadas de la seguridad y la justicia.

\section{REFERENCIAS}

Acosta, D. (2011). Sociología en el penitenciarismo. Prácticas de integración social. Cundinamarca, Colombia: Ministerio de Justicia y Derecho.

Aguilera Torrado, A. (2010). Explicación psicoanalítica del acto criminal. Revista Criminalidad, 52(1), pp. 333-348.

AÑEZ, M. A. \& HAN, P. L. (2011). La Política criminal en Venezuela. Especial referencia a la conflictividad social en torno al delito de secuestro. Política Criminal, 6(11), pp. 19-43.

Ayos, E. J. (2014). Prevención del delito y teorías criminológicas: tres problematizaciones sobre el presente. Estudios Socio-Jurídicos, 16(2), pp. 265-312.

Azaola, E. \& Ruiz, M. A. (2009). Política criminal y sistema penal en México. El Cotidiano, 153, pp. 5-11.

Becker, G. S. (1974). Crime and Punishment: An Economic Approach. En BeCKer, G. S. \& LANDES, W. M. (Eds.), Essays in the Economics of Crime and Punishment (pp. 154). New York: National Bureau of Economic Research. 
Bernardi, A. (2010). Seguridad y derecho penal en Italia y en la Unión Europea. Política Criminal, 5(9), pp. 68-113.

Caldas, J. E. (2014). Una política criminal a partir de los medios masivos de comunicación. En Política criminal y libertad, Cátedra de Investigación Científica del Centro de Investigación en Política Criminal (pp. 307-330). Bogotá: Universidad Externado de Colombia.

Calveiro, P. (2012). Violencias de Estado. La guerra antiterrorista y la guerra contra el crimen como medios de control global. Buenos Aires: Siglo Veintiuno Editores.

Chincoya, H. (2013). ¿Política criminal, política criminológica o políticas públicas en seguridad?: reflexiones en la coyuntura de la redacción del Plan Nacional de Desarrollo 2013-2018. Alegatos, 83, pp. 99-116.

Consejo nacional de Evaluación de la Política de Desarrollo Social/coneval (2016). Modelo de términos de referencia para la evaluación en materia de diseño. En CONEVAL-Evaluación de Programas Sociales. Recuperado de https: / / bit.ly/3vVYORx.

Conferencia Nacional de Procuración de Justicia (2019). Directorio de procuradores y fiscales del país. Recuperado de https://bit.ly/3vWX36N.

De la Barreda, L., Aguilar, J. A., Vélez, A. \& Chávez, E. (2013). El Ministerio Público. Diagnóstico y propuestas para reformarlo. Ciudad de México: UNAM-Programa Universitario de Derechos Humanos.

EhrLICH, I. (1974). Participation in Illegitimate Activities: An Economic Analysis. En BeCKeR, G. S. \& LANDES, W. M. (Eds.), Essays in the Economics of Crime and Punishment (pp. 68-134). New York: National Bureau of Economic Research.

enamorado, T., López Calva, L. F., Rodríguez Castelán, C. \& Winkler, H. (2016). Income inequality and violent crime: Evidence from Mexico's drug war. Journal of Development Economics, 120, pp. 128-143.

FuENTES, D. F. (2003). Políticas públicas y seguridad ciudadana: la violencia como problema público. Estudios Fronterizos, 4(8), pp. 13-31.

GARCía, S. (2002). En torno a la seguridad pública - Desarrollo penal y evolución del delito. En Peñaloza, P. \& Garza, M. (Coords.), Los desafíos de la seguridad pública en México (pp. 81-98). México: Universidad Iberoamericana, Universidad Nacional Autónoma de México, Procuraduría General de la República.

Greenwood, P. W. (2004). Cost-Effective Violence Prevention through Targeted Family Interventions. Annals of the New York Academy of Sciences, 1036(1), pp. 201214. 
Guillén, R. \& Cruz, A. (2008). La justicia penal en México. Un estudio de caso. Ciudad de México: Instituto de Investigaciones Jurídicas.

Gutiérrez, M. (2015). Políticas públicas y prevención en Colombia. En Política criminal y "prevención". Cátedra de Investigación Científica del Centro de Investigación en Política Criminal (pp. 21-43). Bogotá: Universidad Externado de Colombia.

Gutiérrez, M. (2014). Hacia una justicia restaurativa. En Política criminal y libertad, Cátedra de Investigación Científica del Centro de Investigación en Política Criminal (pp. 71-90). Bogotá: Universidad Externado de Colombia.

Hulsman, J. (2014). The menu is not the meal. Deconstruction of a criminal justice system. En Política criminal y libertad, Cátedra de Investigación Científica del Centro de Investigación en Política Criminal (pp. 121-165). Bogotá: Universidad Externado de Colombia.

Kvaraceus, W. C. (1964). La delincuencia de menores. Un problema del mundo moderno. París: Organización de las Naciones Unidas para la Educación, la Ciencia y la Cultura.

Merton, R. K. (1938). Social Structure and Anomie. American Sociological Review, 3(5), pp. 672-682.

MÉxico Evalúa (2014). Prevención del delito en México: ¿Dónde quedó la evidencia? Recuperado de https: / / bit.ly/2SKMA05.

México Evalúa (2015). Prevención del delito en México: ¿Cuáles son las prioridades? Recuperado de https: / / bit.ly/3h1ea3b.

Oficina de las Naciones Unidas COntra la Droga y El Delito (2010). Medidas privativas y no privativas de la libertad. El sistema penitenciario. Manual de instrucciones para la evaluación de la justicia penal. Recuperado de https: / / bit.ly/3o2tvC0.

OJEDA, J. (2012). Reinserción social y función de la pena. En GARCía, S. \& IsLAS, O. (coords.), Derecho penal y criminalística. XII Jornadas sobre Justicia Penal (pp. 67-78). México: Instituto de Investigaciones Jurídicas.

Open Society Justice Initiative (2015). Justicia fallida en el estado de Guerrero. Nueva York: Open Society Foundations.

PÉREZ, C. (2013). Marcando al delincuente: estigmatización, castigo y cumplimiento del derecho. Revista Mexicana de Sociología, 75(2), pp. 287-311.

Quinteros, D. (2014). Delitos del espacio público y el problema de la "cifra negra": una aproximación a la no-denuncia en Chile. Política Criminal, 9(18), pp. 691-712.

SAlgado, J. (2010). Documento conceptual-metodológico sobre políticas públicas de seguridad ciudadana, capacidades institucionales para medir su desempeño y bases para el desarrollo 
de indicadores en esta materia. Reporte de investigación núm. 8 del proyecto "Calidad de gobierno y rendición de cuentas en las entidades federativas de México”. Ciudad de México: CIDE-PNUD.

SÁnchez Ostiz, P. (2007). Principios y reglas de las decisiones de la política criminal. Persona y derecho, 56, pp. 59-102.

Sherman, L. W., Gottfredson, D., MacKenzie, D., Eck, J., Reuter, P. \& Bushway, S. (1997). Preventing crime: what works, what doesn't, what's promising. Washington, D.C.: U.S. Department of Justice, Office of Justice Programs.

Tamarit, J. M. (2007). Política criminal con bases empíricas en España. Política Criminal, 3, pp. 1-16.

Torres, P. R. (2011). Los límites y controles institucionales en el nuevo sistema de justicia penal mexicano. En Consejo de la Judicatura Federal, El nuevo sistema de justicia penal acusatorio, desde la perspectiva constitucional (pp. 97-124). Ciudad de México: Poder Judicial de la Federación.

TORRES, P. R. (coord.) (2014). Políticas públicas para la justicia. Ciudad de México: ITESMINACIPE.

UMAÑA, C. E. (2015). Prevenciones sobre la prevención: algunas consideraciones desde la criminología. En Política criminal y "prevención". Cátedra de Investigación Científica del Centro de Investigación en Política Criminal (pp. 45-87). Bogotá: Universidad Externado de Colombia.

VALDEZ, A. (2000). Seguridad pública y gobernabilidad: teorías, relaciones y aproximaciones. Estudios Políticos, 24, pp. 281-291.

Zaffaroni, E., Alagia, A. \& Slokar, A. (2002). Derecho penal. Parte general (2a ed.). Buenos Aires: Ediar.

ZePEDA, G. (2012). Diagnóstico del sistema penitenciario mexicano. En SÁNCHEZ, A. (coord.), La transformación del sistema penitenciario federal: una visión de Estado (pp. 13-57). México: Centro de Investigación y Estudios en Seguridad. 